\title{
28 Research Square \\ Long-Term Incidence and Timing of Splenic Pseudoaneurysm Formation After Blunt Splenic Injury: A Retrospective, Observational, Descriptive Study
}

\section{Takaki Hirano}

Ohta Nishinouchi Hospital: Ota Nishinouchi Byoin, Tokyo lka Shika Daigaku

Yudai Iwasaki ( $\nabla$ yudai.i0213@gmail.com)

Tohoku University Hospital: Tohoku Daigaku Byoin https://orcid.org/0000-0002-0702-0392

\section{Yuko Ono}

Kobe University: Kobe Daigaku, Fukushima Kenritsu Ika Daigaku

\section{Tokiya Ishida}

Ohta Nishinouchi Hospital: Ota Nishinouchi Byoin, Aichi Ika Daigaku

\section{Kazuaki Shinohara}

Tokyo Ika Shika Daigaku

\section{Original research}

Keywords: blunt splenic injury, splenic pseudoaneurysm, nonoperative management

Posted Date: September 3rd, 2021

DOI: https://doi.org/10.21203/rs.3.rs-806027/v1

License: (c) (i) This work is licensed under a Creative Commons Attribution 4.0 International License. Read Full License 


\section{Abstract \\ Background}

Nonoperative management (NOM) has become a standard strategy for hemodynamically stable patients with blunt splenic injury; however, delayed rupture of splenic pseudoaneurysm (SPA) is a serious complication of NOM. In medical literature, data regarding the long-term incidence of SPA are scarce, and the appropriate timing for performing follow-up contrast-enhanced computed tomography (CT) has not yet been reported. The present study aimed to elucidate the longterm incidence and timing of SPA formation after blunt splenic injury in patients treated with NOM.

\section{Methods}

This retrospective, observational, descriptive study was conducted at a tertiary medical center in Japan. Patients with blunt splenic injury who were treated with NOM in the study setting, between April 2014 and August 2020, were included for the analysis. We performed follow-up contrast-enhanced CT for more than 2 weeks in $65 \%$ cases to detect SPA formation. The primary outcome was the cumulative incidence of delayed formation of SPA. We also evaluated differences in SPA formation between patients who received transcatheter arterial embolization (TAE; TAE group) and those who did not receive it (non-TAE group) on the admission day.

\section{Results}

Among 49 patients with blunt splenic injury who were treated with NOM, 32 underwent follow-up contrast-enhanced CT for over 2 weeks, and 5 of the 32 patients (10.2\%) had delayed formation of SPA. All cases of SPA formation occurred within 15 days of injury. The incidence of SPA formation was not significantly different between the TAE and non-TAE groups $(5.3 \%$ vs. $13.3 \%, p=0.67)$.

\section{Conclusions}

SPA developed in approximately $10 \%$ of patients within 2 weeks after blunt splenic injury. Therefore, performing followup contrast-enhanced CT around this period after injury may be useful to evaluate delayed formation of SPA. Although our findings are novel, they should be confirmed through future studies with a larger sample size.

\section{Background}

Nonoperative management (NOM) has become the standard strategy for hemodynamically stable patients with blunt splenic injury[1, 2]. This management approach originated from the realm of pediatric blunt splenic trauma and had also become widely accepted in adult patients $[2,3]$. However, NOM can sometimes be a failure owing to uncontrollable intraabdominal hemorrhage. To prevent performing surgery for hemostasis, several investigators recommended the selective use of transcatheter arterial embolization (TAE) as an adjunct to NOM. They reported that the use of TAE in cases of high-grade injuries and contrast blush (CB) on computed tomography (CT) resulted in a high success rate of NOM[4-6]. Through the wide use of selective TAE, the overall success rate of NOM in adult patients with blunt splenic injury was reported to be approximately $90 \%[6-10]$. The Eastern Association for the Surgery of Trauma (EAST) practice management guideline recommends that TAE for blunt splenic injury should be considered for patients with the American Association for the Surgery of Trauma (AAST) grade of $>\mathbb{Q}, \mathrm{CB}$, moderate hemoperitoneum, or evidence of ongoing splenic bleeding[2]. 
Despite the high success rates of NOM, delayed rupture of the spleen has become a rare, but serious, complication of NOM. A previous study reported death due to delayed rupture in one of the 303 cases[11]. Several studies have reported that $1-2 \%$ patients were readmitted to the hospital due to post-discharge bleeding and underwent splenectomy[12, 13]. Splenic pseudoaneurysm (SPA) is an aneurysm type without the three vessel layers formed after splenic injury, and rupture of the SPA can be the cause of delayed rupture of the spleen[14]. A few retrospective observational studies indicated that SPA developed within approximately a week after injury $[8,15]$. Consistent with these findings, another report presented a case of delayed SPA formation detected on day 5 after injury[16].

However, the long-term incidence and timing of delayed SPA formation are poorly understood. Moreover, the optimal timing for CT re-examination and follow-up period for SPA detection also remain controversial[17]. The EAST practice management guidelines state that the need for repeated imaging remains an unanswered question[2]. In our institution, we conduct a follow-up of these patients using long-term CT findings according to the injury severity. However, the effectiveness of this management approach remains unclear.

Therefore, we aimed to determine the long-term incidence and timing of delayed SPA formation after blunt splenic injury treated with NOM by utilizing repeated follow-up contrast-enhanced CT findings. We also aimed to investigate the appropriate timing for performing CT re-examination.

\section{Methods}

This retrospective, observational, descriptive study was conducted at a tertiary care facility in Japan. Annually, our institution receives approximately 5,000 patients through ambulance services, including 1,100-1,200 trauma patients with various degrees of severities. The review board at Ohta Nishinouchi Hospital (Fukushima, Japan) approved this study on April 15, 2020 (Approval No. 40). The committee waived the need for patient consent.

The study included patients with blunt splenic trauma who were admitted to our intensive care unit and were treated with NOM between April 2014 and August 2020. NOM was defined as a management approach without involving emergency abdominal surgery. Patients who were directly transported from the emergency department to the operation room for emergency abdominal surgery were excluded from the study, as were those who died within the first 24 hours from arrival to the hospital. The therapeutic decision for NOM was determined by each physician's discretion based on their experience and the trauma severity. Patients who were treated with NOM underwent meticulous monitoring of hemodynamic parameters, serial abdominal findings, and repeated blood tests including tests for hemoglobin and coagulation factor levels.

Data were collected from our hospital-based trauma database and patients' electronic healthcare records. Patients' characteristics included age, sex, comorbidity, injury mechanism, severity of injury, grade of splenic injury based on the AAST grade, presence of CB on CT, indication for angiography and TAE, NOM failure, angiographic findings, duration of hospital stay, and mortality. In our institution, indications for emergency TAE, defined as TAE within 24 hours after arrival to the hospital, were generally considered based on hemodynamic parameters, high injury grade, and CB detection on contrast-enhanced CT. Patients who subsequently underwent any abdominal surgery after admission were classified as having NOM failure. Radiologic findings including splenic injury grade and presence of SPA formation or CB were interpreted by two doctors: one was a board-certified emergency physician and the other was a board-certified interventional radiologist.

The primary outcome was the cumulative incidence of delayed formation of SPA. We conducted a follow-up of the included patients with repeated contrast-enhanced CT for a long period to detect SPA formation. Although the timing and duration of the follow-up CT were based on physicians' discretion, we conducted the follow-up for more than two weeks in many cases even if the patient had been discharged. The primary outcome was assessed based on the 
findings of follow-up CT. The timing and duration of follow-up CT were determined based on the severity of the injury grade, initial CT findings, and need for emergency TAE. Delayed formation of SPA was defined as an SPA that was first detected on a contrast-enhanced CT scan beyond 48 hours after injury according to a previous study[11]. We also examined the differences in the cumulative incidence of SPA formation between patients who received TAE (TAE group) and those who did not received it (non-TAE group) on the admission day.

Continuous variables are expressed as mean \pm standard deviation (SD) or as median with the 1 st and 3rd quartiles. Categorical variables are expressed as number and proportion. Differences between TAE group and non-TAE group in continuous variables were compared using Student's $t$ test or the Wilcoxon rank-sum test based on data distribution for each variable. The Shapiro-Wilk test was used to verify the data distribution. The cumulative incidence of SPA was assessed using the Kaplan-Meier method, and between-group differences were compared using the log-rank test. Twosided $\mathrm{P}$ values of $<0.05$ were considered to indicate statistical significance. All statistical analyses were performed using R software (version 4.0.4).

\section{Results}

\section{Patient characteristics and SPA formation}

A total of 49 patients with blunt splenic injury treated with NOM were included in this study (Fig. 1). Patient demographics are summarized in Table 1. The mean age of the entire cohort was 41.0 (SD: 21.7) years old, and 75.5\% of the patients were male. The mean injury severity score (ISS) was 29.6 (SD: 11.1). The predominant mechanism of injury was traffic accident (42 of $49,85.7 \%)$. Regarding splenic injury grade, five patients $(10.2 \%)$ were classified as grade $\varangle, 24$ patients $(49.0 \%)$ as grade $\nabla, 11(22.4 \%)$ patients as grade $\nabla$, nine $(18.4 \%)$ patients as grade $\nabla$, and no patient as grade $\Downarrow$. Only one patient had failure of $\operatorname{NOM}(1$ of $51,2.0 \%)$ and, therefore, underwent distal pancreatectomy together with splenectomy for pancreatic injury rather than for splenic injury. Only one patient died due to multiple organ failure at 51 days after injury. Nineteen patients (38.8\%) received emergency TAE as an adjunct to NOM. Although there was no significant difference in the demographic characteristics between patients with or without emergency TAE, those who received emergency TAE had a higher splenic injury grade (Table 1). 
Table 1

Characteristics of patients with and without emergency transcatheter arterial embolization.

\begin{tabular}{|c|c|c|c|c|}
\hline & Total & Emergency TAI & & \\
\hline & & No & Yes & \\
\hline Variable & $N=49$ & $\mathrm{n}=\mathbf{3 0}$ & $n=19$ & $\mathrm{p}$ \\
\hline Age, years, mean (SD) & $40.96(21.65)$ & $44.37(23.25)$ & $35.58(18.14)$ & 0.17 \\
\hline Male, n (\%) & $37(75.5)$ & $20(66.7)$ & $17(89.5)$ & 0.14 \\
\hline Hypertension, n (\%) & $9(18.4)$ & $8(26.7)$ & $1(5.3)$ & 0.13 \\
\hline Diabetes mellitus, $n(\%)$ & $7(14.3)$ & $5(16.7)$ & $2(10.5)$ & 0.86 \\
\hline Hematologic disease, n (\%) & $1(2.0)$ & $1(3.3)$ & $0(0.0)$ & 1.0 \\
\hline Liver disease, $\mathrm{n}(\%)$ & $1(2.0)$ & $1(3.3)$ & $0(0.0)$ & 1.0 \\
\hline Charlson Risk Index, n (\%) & & & & 0.57 \\
\hline 0 & $39(79.6)$ & $23(76.7)$ & $16(84.2)$ & \\
\hline 1 & $7(14.3)$ & $4(13.3)$ & $3(15.8)$ & \\
\hline 2 & $2(4.1)$ & $2(6.7)$ & $0(0.0)$ & \\
\hline 3 & $1(2.0)$ & $1(3.3)$ & $0(0.0)$ & \\
\hline Mechanism, n (\%) & & & & 0.64 \\
\hline Traffic accident & $42(85.7)$ & $25(83.3)$ & $17(89.5)$ & \\
\hline Fall & $5(10.2)$ & $4(13.3)$ & $1(5.3)$ & \\
\hline Others & $2(4.1)$ & $1(3.3)$ & $1(5.3)$ & \\
\hline SBP on admission, $n(\%)$ & & & & 0.44 \\
\hline $0 \mathrm{mmHg}$ & $0(0)$ & $0(0)$ & $0(0)$ & \\
\hline $1-49 \mathrm{mmHg}$ & $0(0)$ & $0(0)$ & $0(0)$ & \\
\hline $50-75 \mathrm{mmHg}$ & $3(6.1)$ & $2(6.7)$ & $1(5.3)$ & \\
\hline 76-89 mmHg & $1(2.0)$ & $0(0.0)$ & $1(5.3)$ & \\
\hline$>89 \mathrm{mmHg}$ & $45(91.8)$ & $28(93.3)$ & $17(89.5)$ & \\
\hline GCS on admission, $\mathrm{n}(\%)$ & & & & 0.87 \\
\hline 3 & $3(6.1)$ & $2(6.7)$ & $1(5.0)$ & \\
\hline $4-5$ & $1(2.0)$ & $1(3.3)$ & $0(0.0)$ & \\
\hline $6-8$ & $0(0)$ & $0(0)$ & $0(0)$ & \\
\hline $9-12$ & $5(10.2)$ & $3(10.0)$ & $2(10.5)$ & \\
\hline
\end{tabular}

SBP, systolic blood pressure; GCS, Glasgow Coma Scale; RR, respiratory rate; RTS, Revised Trauma Score; TRISS, Trauma and Injury Severity Score; AIS, Abbreviated Injury Scale; ISS, Injury Severity Score; AAST, the American Association for the Surgery of Trauma; TAE, transcatheter arterial embolization; NOM, nonoperative management; ICU, intensive care unit; SD, standard deviation; IQR, interquartile range 


\begin{tabular}{|c|c|c|c|c|}
\hline & \multirow[t]{2}{*}{ Total } & \multicolumn{3}{|l|}{ Emergency TAE } \\
\hline & & No & Yes & \\
\hline $13-15$ & $40(81.6)$ & $24(80.0)$ & $16(84.2)$ & \\
\hline RR on admission, $n$ (\%) & & & & 0.18 \\
\hline $0 \mathrm{bpm}$ & $0(0)$ & $0(0)$ & $0(0)$ & \\
\hline $1-5 \mathrm{bpm}$ & $0(0)$ & $0(0)$ & $0(0)$ & \\
\hline $6-9 \mathrm{bpm}$ & $0(0)$ & $0(0)$ & $0(0)$ & \\
\hline $10-29 \mathrm{bpm}$ & $35(71.4)$ & $24(80.0)$ & $11(57.9)$ & \\
\hline$>29 \mathrm{bpm}$ & $14(28.6)$ & $6(20.0)$ & $8(42.1)$ & \\
\hline RTS, median [IQR] & $7.84[7.55,7.84]$ & $7.84[7.55,7.84]$ & $7.84[7.55,7.84]$ & 0.77 \\
\hline TRISS, median [IQR] & $0.95[0.85,0.98]$ & $0.94[0.79,0.98]$ & $0.95[0.88,0.98]$ & 0.55 \\
\hline AIS abdomen, $\mathrm{n}(\%)$ & & & & 0.090 \\
\hline 0 & $1(2.0)$ & $1(3.3)$ & $0(0.0)$ & \\
\hline 1 & $0(0)$ & $0(0)$ & $0(0)$ & \\
\hline 2 & $13(26.5)$ & $11(36.7)$ & $2(10.5)$ & \\
\hline 3 & $20(40.8)$ & $12(40.0)$ & $8(42.1)$ & \\
\hline 4 & $15(30.6)$ & $6(20.0)$ & $9(47.4)$ & \\
\hline 5 & $0(0)$ & $0(0)$ & $0(0)$ & \\
\hline 6 & $0(0)$ & $0(0)$ & $0(0)$ & \\
\hline ISS, mean (SD) & $29.59(11.11)$ & $29.17(12.06)$ & $30.26(9.70)$ & 0.74 \\
\hline Splenic injury grade (AAST), $\mathrm{n}(\%)$ & & & & 0.002 \\
\hline 口 & $5(10.2)$ & $5(16.7)$ & $0(0.0)$ & \\
\hline 口 & $24(49.0)$ & $19(63.3)$ & $5(26.3)$ & \\
\hline 口 & $11(22.4)$ & $4(13.3)$ & $7(36.8)$ & \\
\hline 口 & $9(18.4)$ & $2(6.7)$ & $7(36.8)$ & \\
\hline 口 & $0(0)$ & $0(0.0)$ & $0(0.0)$ & \\
\hline Emergency angiography, $\mathrm{n}(\%)$ & $29(59.2)$ & $10(33.3)$ & $19(100.0)$ & $<0.001$ \\
\hline Emergency TAE, n (\%) & $19(38.8)$ & & & \\
\hline Surgery (NOM failure), n (\%) & $1(2.0)$ & $0(0.0)$ & $1(5.3)$ & 0.82 \\
\hline Delayed formation of SPA, $n$ (\%) & $5(10.2)$ & $4(13.3)$ & $1(5.3)$ & 0.67 \\
\hline
\end{tabular}

SBP, systolic blood pressure; GCS, Glasgow Coma Scale; RR, respiratory rate; RTS, Revised Trauma Score; TRISS, Trauma and Injury Severity Score; AIS, Abbreviated Injury Scale; ISS, Injury Severity Score; AAST, the American Association for the Surgery of Trauma; TAE, transcatheter arterial embolization; NOM, nonoperative management; ICU, intensive care unit; SD, standard deviation; IQR, interquartile range 


\begin{tabular}{|c|c|c|c|c|}
\hline & \multirow[t]{2}{*}{ Total } & \multicolumn{3}{|l|}{ Emergency TAE } \\
\hline & & No & Yes & \\
\hline Duration of hospital, median [IQR] & $36.00[15.00,64.00]$ & $33.00[17.50,64.00]$ & $39.00[14.00,67.00]$ & 0.94 \\
\hline Duration of ICU, median [IQR] & $3.00[2.00,5.00]$ & $3.00[2.00,4.00]$ & $4.00[3.00,5.50]$ & 0.056 \\
\hline 30-day mortality, n (\%) & $0(0.0)$ & $0(0.0)$ & $0(0.0)$ & NA \\
\hline 180-day mortality, n (\%) & $1(2.0)$ & $1(3.3)$ & $0(0.0)$ & 1.0 \\
\hline \multicolumn{5}{|c|}{$\begin{array}{l}\text { SBP, systolic blood pressure; GCS, Glasgow Coma Scale; RR, respiratory rate; RTS, Revised Trauma Score; TRISS, } \\
\text { Trauma and Injury Severity Score; AIS, Abbreviated Injury Scale; ISS, Injury Severity Score; AAST, the American } \\
\text { Association for the Surgery of Trauma; TAE, transcatheter arterial embolization; NOM, nonoperative management; } \\
\text { ICU, intensive care unit; SD, standard deviation; IQR, interquartile range }\end{array}$} \\
\hline
\end{tabular}

All patients underwent the follow-up while we conducted the follow-up for 32 patients with contrast-enhanced CT over 2 weeks, and the longest follow-up duration was 1170 days. Delayed SPA formation occurred in five (10.2\%) patients, and all cases of SPA formations occurred within 15 days of injury (range, 8-15 days). The details of the dates of SPA formation in each of the 5 cases are shown in Table 2. No SPA formation was detected after this period even with repeated contrast-enhanced CT and long-term follow-up. The Kaplan-Meier curve showed information of the cumulative incidence of delayed formation of SPA in the total cohort (Fig. 2).

Table 2

Characteristics of five patients who had delayed SPA formation.

\begin{tabular}{|llllllllll|}
\hline $\begin{array}{l}\text { Age } \\
\text { (years) }\end{array}$ & Sex & Mechanism & AIS & $\begin{array}{l}\text { ISS } \\
\text { abdomen }\end{array}$ & $\begin{array}{l}\text { Splenic } \\
\text { injury } \\
\text { grade } \\
\text { (AAST) }\end{array}$ & $\begin{array}{l}\text { Emergency } \\
\text { TAE }\end{array}$ & $\begin{array}{l}\text { The day } \\
\text { SPA was } \\
\text { diagnosed }\end{array}$ & $\begin{array}{l}\text { Management } \\
\text { for SPA }\end{array}$ & $\begin{array}{l}\text { Success } \\
\text { of NOM }\end{array}$ \\
\hline 68 & M & Fall & 4 & 24 & $\square$ & No & 10 & TAE & Yes \\
\hline 17 & F & Traffic & 3 & 14 & $\square$ & No & 8 & Observation & Yes \\
\hline 57 & M & Others & 2 & 29 & $\square$ & No & 15 & TAE & Yes \\
\hline 43 & M & Traffic & 3 & 29 & $\square$ & No & 9 & TAE & Yes \\
\hline 17 & M & Traffic & 4 & 24 & $\square$ & Yes & 11 & TAE & Yes \\
\hline $\begin{array}{l}\text { AIS, Abbreviated Injury Scale; ISS, Injury Severity Score; AAST, American Association for the Surgery of Trauma; TAE, } \\
\text { transcatheter arterial embolization; NOM, nonoperative management; SPA, splenic pseudoaneurysm. }\end{array}$ \\
\hline
\end{tabular}

The cumulative incidence of delayed formation of SPA in patients stratified by emergency TAE is shown in Fig. 3.

Although the difference did not reach statistical significance, patients who did not receive emergency TAE tended to have a higher cumulative incidence of SPA than those who received it (5.3\% vs. $13.3 \%, p=0.67)$.

\section{Clinical course of the delayed formation of SPA}

The characteristics of the five injured patients who developed SPA are listed in Table 2. Delayed formation of SPA was

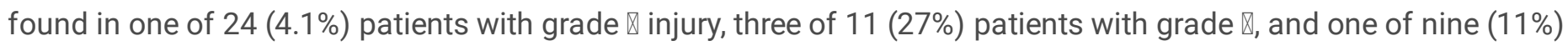
patients with grade $\nabla$ in terms of splenic injury grade. There was no delayed formation of SPA in patients with grade $\nabla$ injury. Of the five patients, emergency TAE was performed during the first admission in one patient only (20\%). The 
remaining four patients with SPA were managed by selective TAE. One patient was managed only by observation, and the SPA disappeared spontaneously.

\section{Discussion}

Our study demonstrated the long-term incidence and timing of SPA formation after blunt splenic injury treated with NOM. Five of 49 patients developed SPA during the follow-up period, and delayed rupture was not observed in our study cohort. The incidence of delayed SPA formation was in agreement with the findings of previous studies[8, 15, 18, 19]. We believe that our study reports two clinically important findings: The first finding was that SPA formation occurred within 15 days (range, 8-15 days). The second finding was that TAE application during hospital admission tended to reduce the formation of SPA.

Most cases of delayed SPA formation were detected approximately within a week of injury[8, 15]. Based on these data, some studies recommend performing follow-up CT approximately a week later after injury[15]or within 48 hours after admission[18]. However, the timing of SPA formation in our study was later than that reported in published studies. This finding suggests that performing follow-up contrast-enhanced CT after approximately 2 weeks, in addition to performing one at 48 hours or at 1 week, might be a useful approach to evaluate delayed formation of SPA. This difference might have been due to the variation in patients' severity. The guideline states that hemodynamically unstable patients should be managed with urgent laparotomy[2]. According to the guidelines, previous studies[8,15, 18] were limited in terms of the adaptation of NOM to hemodynamically stable patients. Compared with them, NOM for TAE was chosen even in patients with hemodynamic instability in our institution. Due to this difference in NOM indication, more severe patients might have been included in this study. In fact, the median value of ISS was 30 in our study, and this value tended to be higher than that reported in previous studies[8, 18]. Moreover, our finding suggested that performing routine follow-up CT after approximately 2 weeks of injury may not be necessary. In previous studies[8, 15], the maximum period for follow-up CT was limited to within 25 days because follow-up CT was performed during only intensive care unit stay or hospital stay. In contrast, we performed follow-up contrast-enhanced CT in 32 of 49 patients for more than 2 weeks, for up to 1170 days, even if the patient had been discharged. However, no patient developed SPA after 15 days.

The trauma severity in patients with emergency TAE was more severe than that in patients without the emergency TAE. Nonetheless, patients who received the emergency TAE tended to have a lower incidence of delayed SPA formation than those who did not receive the emergency TAE in our study. Although the incidence of SPA formation was not significantly different between the two groups, emergency TAE might have an essential role in preventing subsequent SPA formation. This result was supported by the fact that adjunctive TAE improved NOM success rates[4-6] and that SPA rupture was the main cause of NOM failure[8]. Indeed, the NOM failure rate in all patients in this study was $2.0 \%$ (1 of 49 patients), which is lower than that of $8.3 \%$ (95\% confidence interval, 6.7-10.2) reported in a previous metaanalysis[7]. This discrepancy may have been due to differences in the initial TAE indication. In our institution, emergency TAE is generally performed even for grade $\triangle$ injury patients. Briefly, emergency TAE is also applied to patients who should have undergone laparotomy according to the guideline. This inclusion criterion is slightly more aggressive than the EAST guideline recommendation[2]. By contrast, the previous meta-analysis[7] included observational studies wherein TAE was not applied for high-grade injury patients. Therefore, a large prospective observational study or a randomized controlled study is needed to confirm the utility of TAE to prevent SPA formation.

This study had several limitations. First, our study had a retrospective descriptive design, and we did not follow any strict protocol for NOM management and TAE indication. Decision making for TAE induction depended on the physician's discretion. Consequently, patients with more severe conditions might have been managed by NOM together with TAE instead of operative management in the present study compared to that in previous studies. Therefore, caution should be exercised during the generalization of our findings in terms of the incidence and timing of SPA formation. However, 
the incidence of SPA observed in this study was in agreement with that of previous studies[8,15, 18, 19]. Hence, we believe that our findings can be applied to most patients with blunt splenic injury, even though the strategy followed was slightly different. The second limitation was the variation in the timing and frequency of performing follow-up CT. In our institution, patients considered to be at high risk of SPA formation (e.g., high-grade injury or presence of CB at the initial $\mathrm{CT}$ ) tended to have a long follow-up period. While this trend was reasonable in clinical practice, we could not set the schedule of the follow-up CT at a constant timing. Some patients did not visit our institution, which might lead to withdrawal bias. In fact, among all 49 patients, follow-up CT over 60 days was performed only in 20 patients in our analysis. However, we could conduct the follow-up for approximately $70 \%$ of patients for more than 2 weeks, and SPA formation was not detected after 15 days from injury onset. This effect of withdrawal bias was considered to be small. The third limitation was the small number of eligible patients and the single-center study. Therefore, the results of this study may not be generalizable to other settings.

Despite these limitations, this study has strengths, as it was the first observational study to evaluate the long-term clinical history of SPA after blunt splenic injury treated with NOM by utilizing long-term repeat contrast-enhanced CT. Thus far, no previous studies have conducted follow-up contrast-enhanced CT for patients until after discharge or confirmed whether SPAs were formed in the long-term. Our findings may have clinical implications in terms of the duration of follow-up CT in case of blunt splenic injury treated with NOM. A large-sample, multicenter prospective trial is warranted to confirm our findings.

\section{Conclusions}

In conclusion, we demonstrated the long-term incidence and timing of delayed SPA formation after blunt splenic injury treated with NOM. Delayed SPA formation was detected within 15 days after injury onset. Our results suggested that performing follow-up contrast-enhanced CT within approximately 2 weeks after injury onset might be useful to detect delayed SPA formation.

\section{List Of Abbreviations}

American Association for the Surgery of Trauma (AAST)

Computed tomography (CT)

Contrast blush (CB)

Eastern Association for the Surgery of Trauma (EAST)

Injury severity score (ISS)

Nonoperative management (NOM)

Splenic pseudoaneurysm (SPA)

Standard deviation (SD)

Transcatheter arterial embolization (TAE)

\section{Declarations}

Ethics approval and consent to participate

Page 9/14 
This study was approved by the Institutional Review Board at Ohta Nishinouchi Hospital (No. 40) on April 15, 2021. The committee waived the need for patient consent.

\section{Consent for publication}

Consent for publication was not applicable because this manuscript did not obtain individual patient's data.

\section{Availability of data and materials}

The datasets generated during and/or analyzed during the current study are available from the corresponding author on reasonable request.

\section{Competing Interests}

The authors declare that they have no competing interests.

\section{Funding}

This research did not receive any specific grant from funding agencies in the public, commercial, or not-for-profit sectors.

\section{Authors' Contributions}

We thank our colleagues at the Department of Anesthesiology and Emergency Medicine, Ohta Nishinouchi Hospital, for their assistance in data acquisition and for their contribution to this study.

\section{Acknowledgements}

We thank our colleagues at the Department of Anesthesiology and Emergency Medicine, Ohta Nishinouchi Hospital, for their assistance in data acquisition and for their contribution to this study.

\section{References}

1. Watson GA, Hoffman MK, Peitzman AB. Nonoperative management of blunt splenic injury: what is new? Eur $\mathrm{J}$ Trauma Emerg Surg. 2015;41:219-28.

2. Stassen NA, Bhullar I, Cheng JD, Crandall ML, Friese RS, Guillamondegui OD, et al. Selective nonoperative management of blunt splenic injury: an Eastern Association for the Surgery of Trauma practice management guideline. J Trauma Acute Care Surg. 2012;73:294-300.

3. Lynn KN, Werder GM, Callaghan RM, Sullivan AN, Jafri ZH, Bloom DA. Pediatric blunt splenic trauma: a comprehensive review. Pediatr Radiol. 2009;39:904 - 16; quiz 1029-30..

4. Bhullar IS, Frykberg ER, Siragusa D, Chesire D, Paul J, Tepas JJ 3. Selective angiographic embolization of blunt splenic traumatic injuries in adults decreases failure rate of nonoperative management. J Trauma Acute Care Surg. 2012;72:1127-34. rd, et al.

5. Bhullar IS, Frykberg ER, Tepas JJ 3rd, Siragusa D, Loper T, Kerwin AJ. At first blush: absence of computed tomography contrast extravasation in grade IV or V adult blunt splenic trauma should not preclude angioembolization. J Trauma Acute Care Surg. 2013;74:105 - 11; discussion 11 - 2.

6. Dent D, Alsabrook G, Erickson BA, Myers J, Wholey M, Stewart R, et al. Blunt splenic injuries: high nonoperative management rate can be achieved with selective embolization. J Trauma. 2004;56:1063-7. 
7. Requarth JA, D'Agostino RB Jr, Miller PR. Nonoperative management of adult blunt splenic injury with and without splenic artery embolotherapy: a meta-analysis. J Trauma. 2011;71:898-903. discussion.

8. Davis KA, Fabian TC, Croce MA, Gavant ML, Flick PA, Minard G, et al. Improved success in nonoperative management of blunt splenic injuries: embolization of splenic artery pseudoaneurysms. J Trauma. 1998;44:100813. discussion $13-5$.

9. Miller PR, Chang MC, Hoth JJ, Mowery NT, Hildreth AN, Martin RS, et al. Prospective trial of angiography and embolization for all grade III to $\mathrm{V}$ blunt splenic injuries: nonoperative management success rate is significantly improved. J Am Coll Surg. 2014;218:644-8.

10. Gaarder C, Dormagen JB, Eken T, Skaga NO, Klow NE, Pillgram-Larsen J, et al. Nonoperative management of splenic injuries: improved results with angioembolization. J Trauma. 2006;61:192-8.

11. Davies DA, Fecteau A, Himidan S, Mikrogianakis A, Wales PW. What's the incidence of delayed splenic bleeding in children after blunt trauma? An institutional experience and review of the literature. J Trauma. 2009;67:573-7.

12. Zarzaur BL, Vashi S, Magnotti LJ, Croce MA, Fabian TC. The real risk of splenectomy after discharge home following nonoperative management of blunt splenic injury. J Trauma. 2009;66:1531-6. discussion 6-8.

13. Mclntyre LK, Schiff M, Jurkovich GJ. Failure of nonoperative management of splenic injuries: causes and consequences. Arch Surg. 2005;140:563-8. discussion 8-9.

14. Hiraide A, Yamamoto H, Yahata K, Yoshioka T, Sugimoto T. Delayed rupture of the spleen caused by an intrasplenic pseudoaneurysm following blunt trauma: case report. J Trauma. 1994;36:743-4.

15. Muroya T, Ogura H, Shimizu K, Tasaki O, Kuwagata Y, Fuse T, et al. Delayed formation of splenic pseudoaneurysm following nonoperative management in blunt splenic injury: multi-institutional study in Osaka, Japan. J Trauma Acute Care Surg. 2013;75:417-20.

16. Inoue Y, Ikegawa H, Ukai I, Yoshiya K, Sumi Y, Ogura H, et al. Spontaneous occlusion of splenic and renal pseudoaneurysm after blunt abdominal trauma: a case report and literature review. J Emerg Med. 2010;38:e17-22.

17. Zarzaur BL, Kozar RA, Fabian TC, Coimbra R. A survey of American Association for the Surgery of Trauma member practices in the management of blunt splenic injury. J Trauma. 2011;70:1026-31.

18. Leeper WR, Leeper TJ, Ouellette D, Moffat B, Sivakumaran T, Charyk-Stewart T, et al. Delayed hemorrhagic complications in the nonoperative management of blunt splenic trauma: early screening leads to a decrease in failure rate. J Trauma Acute Care Surg. 2014;76:1349-53.

19. Weinberg JA, Lockhart ME, Parmar AD, Griffin RL, Melton SM, Vandromme MJ, et al. Computed tomography identification of latent pseudoaneurysm after blunt splenic injury: pathology or technology? J Trauma. 2010;68:1112-6.

\section{Figures}




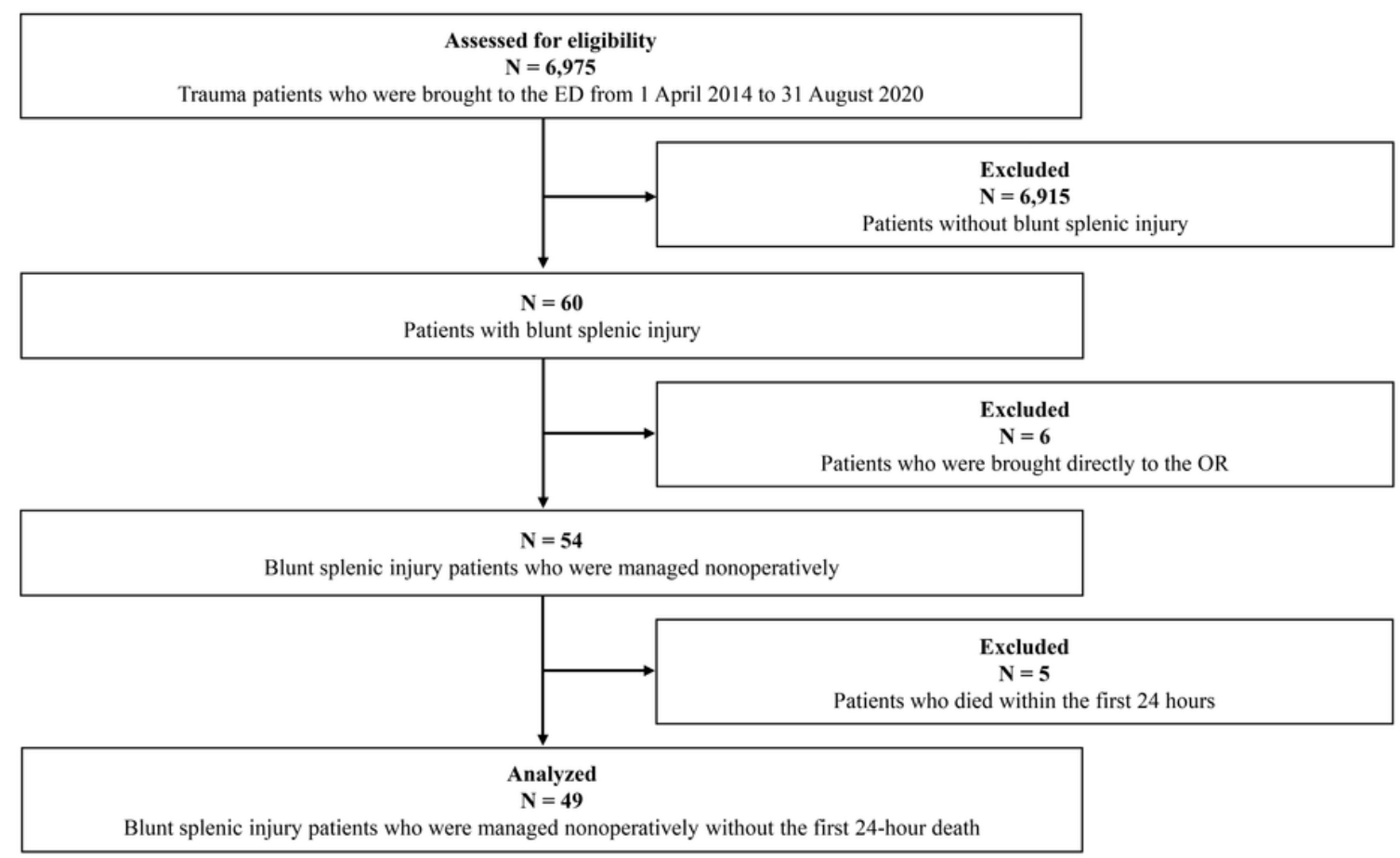

\section{Figure 1}

Flowchart showing the selection of patients with blunt splenic injury for inclusion in the analysis. ED, emergency department; OR, operating room. 


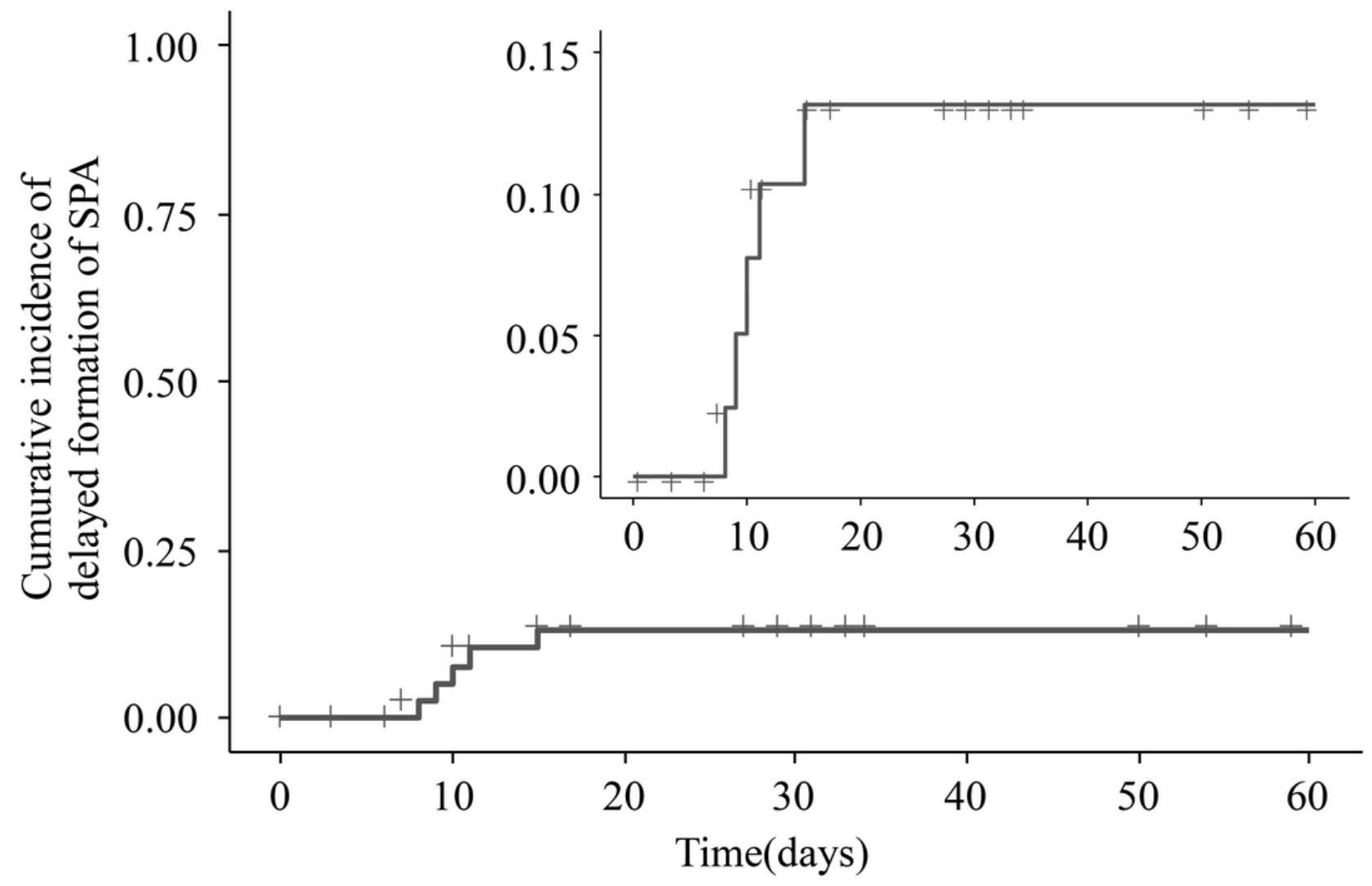

Number at risk

\begin{tabular}{rrrrrrr}
49 & 36 & 29 & 27 & 22 & 22 & 20 \\
\hline 0 & 10 & 20 & 30 & 40 & 50 & 60
\end{tabular}

Figure 2

Cumulative incidence of delayed formation of splenic pseudoaneurysm (SPA) in the total cohort. The inset in the figure shows the same data on an enlarged $\mathrm{Y}$-axis. 


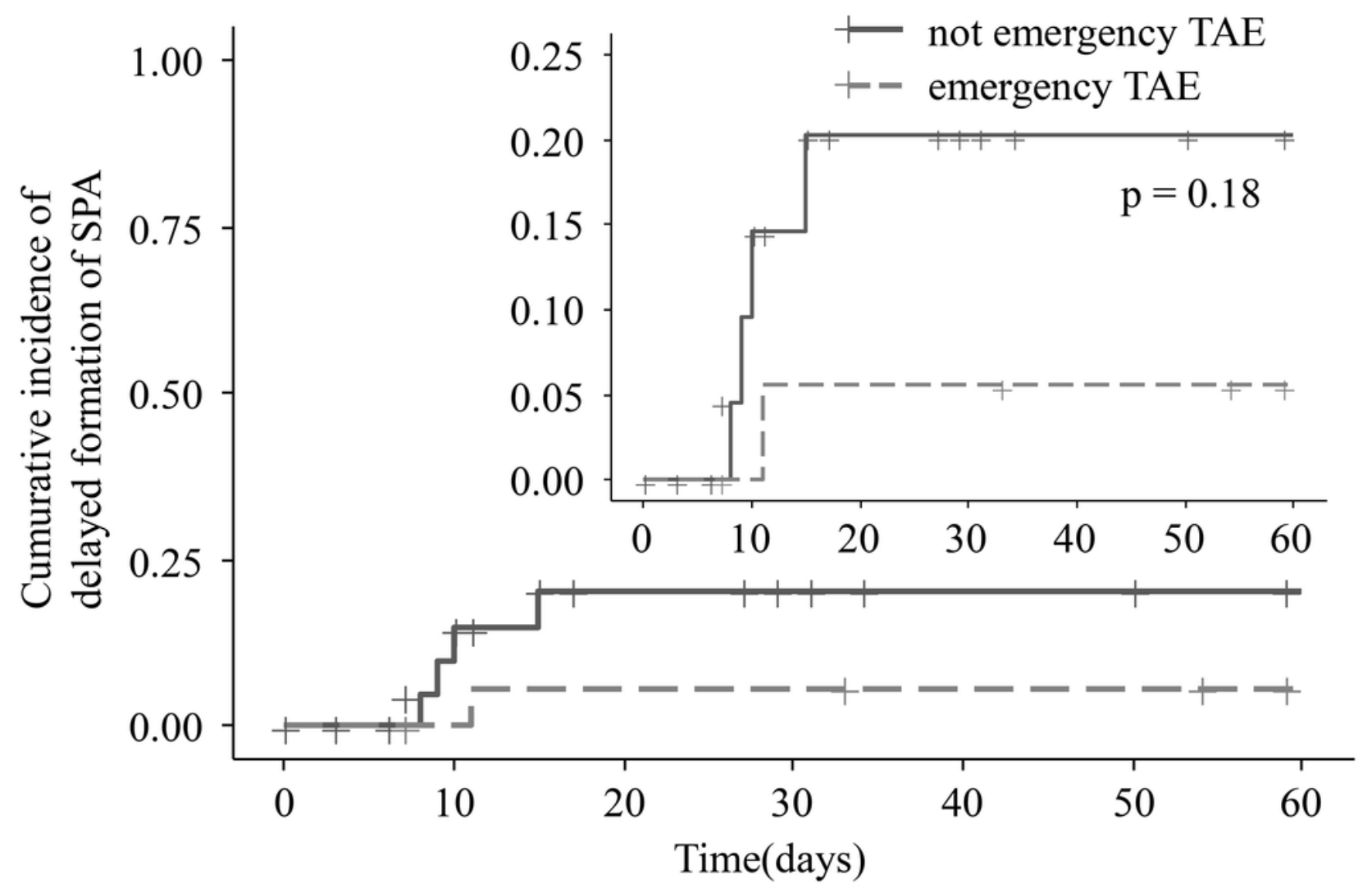

Number at risk

\begin{tabular}{r|ccccccc} 
not emergency TAE & 30 & 18 & 12 & 10 & 6 & 6 & 5 \\
emergency TAE & 19 & 18 & 17 & 17 & 16 & 16 & 15 \\
\cline { 2 - 8 } & 0 & 10 & 20 & 30 & 40 & 50 & 60
\end{tabular}

Figure 3

Cumulative incidence of delayed formation of splenic pseudoaneurysm (SPA), stratified by transcatheter arterial embolization (TAE). The inset in the figure shows the same data on an enlarged $\mathrm{Y}$-axis. 